\title{
Training Model of Innovative and Pioneering Personnel Cultivation in Digital Printing Industry
}

\author{
Guohua Song \\ Jilin Teachers' institute of engineering and technology Changchun, Jilin 130052
}

1244534499@qq.com

Keywords: Digital printing; Personnel training; Model transformation

\begin{abstract}
With the rapid development of computer technology, the printing industry ushered in the digital age, the printing industry personnel training model must be innovated by reforming teaching concept, creating new training system, applying practical teaching methods, constructing teaching staff to shift from college training model to lifelong training model.This article is the phased result of research subject of Jilin Educational Science of 13th Five Year Plan in 2016, Construction of Practical Teaching System in Digital Printing, Based on School-enterprise Integration--- A Case Study of Editing and Publishing Major.
\end{abstract}

\section{Introduction}

Digital printing refers to the printing technique that directly records digital and graphic information on a printed material [1] which achieves two features of "printing on demand" and "plateless printing". It hits a symbolic milestone in the history of printing technology development. As a product of modern science and technology, what digital printing industry demands from practitioners is different from traditional printing era. According to statistics, China's digital printing industry needs 2000000 professional personnel to support its development while actually the number of the professionals who master printing technology is less than 15000 . But at present there are more than 70 colleges and universities graduating more than 20000 students, which cannot meet the demand for professionals in the development of digital printing industry.

\section{Current Situation of Printing Industry}

As the digital printing industry developed in a large scale, employees engaged in digital printing gradually increased. What are their present situation and what influences they have on the development of digital printing industry?

Professional Brain Drain. From the type of staff, the number of the management personnel is more than that of technical personnel. Digital printing is light industry, and technology is the key productivity. Therefore, the lack of technical personnel will become the biggest bottleneck in the development of enterprises. But in reality, management staff tends to be more than technical staff. One case is half-way loss which is common. Technical personnel, after years of accumulated experience, either transfer to management staff, or leave the digital printing industry. Another case is source loss. Deeply influenced by our country's traditional concepts of education, some of the students prefer to major in printing management. While science students tend more to choose machinery, electronics and other popular majors as their major and ignore the relevant printing technology.

Professionals' Difficulty in Adapting to Social Competition. rom the employers' feedback information, technologically highly developed digital printing industry doesn't lack professional graduates whose skills learned in colleges and universities have already lagged behind the industrial developmental demands. As a result, after entering work world the transitional period form college students to social people is becoming longer. In addition, many professionals in the printing industry don't have enough technical innovation capability. Their techniques are comparatively out of date. Being fettered by old conventions leads to the professionals' difficulty in adaption to changes in the industry development. 
High Failure Rate in the Digital Printing Industry Business. With the development of Internet technology, based on the "plateless printing" feature, the digital printing industry is evolving to the individual business model. Internet brings unlimited possibilities, it also brings severe social competition. With rich imagination and courage many students in digital printing industry choose to start up their own businesses after graduation. However, due to lack of social experience, infirm foundation, backward technology and other factors, the failure rate is higher. High failure rate is becoming unfavorable factors of digital printing business.

\section{Reasons of Shortage of Digital Printing Professionals}

Digital printing has become the mainstream of the printing industry, more and more people are engaged in this industry. The training of digital printing personnel in institutions of higher learning and social institutions is not enough and there are many problems in personnel training model. The main reasons can be summarized as follows:

Backward Occupation Concept. That white-collars are superior to blue-collar is deeply rooted in the occupation concept in our country. Influenced by this idea, many parents do not want their children to engage in technical work but guide the children to engage in management occupations. Although digital printing is digital technology-based career, it still cannot achieve the desired standards in the eyes of many people. From the educational concept, the schools do not fulfill their responsibilities, failing to build career plans for their students with positive energy. As a result the students cannot have an accurate understanding of the digital printing industry, inevitably leading to the phenomenon major change half-way.

"Theory-stressed, Practice-Ignored" Teaching Mode. Not only in digital printing industry, but in vast majority of colleges and universities exists " theory-stressed, practice-ignored" educational idea. At present the majority of higher educational institutions which set up digital printing major are higher vocational colleges the feature of which is highlighting occupation and employment-oriented teaching model. This is good both for future employment of the students and planning self-occupational development in advance. But because of the" theory-stressed, practice-ignored" teaching mode, these vocational colleges fail to highlight their practice teaching feature. As a result of this, the students' practical ability is not strong enough to compete in social competition.

Weak Learning Awareness. Digital printing technology develops very rapidly based on the rapid development of computer technology and Internet technology. The practitioners must have consciousness to learn in advance and keep learning to keep up with the pace of technological innovation. Current professionals' difficulty in adapting to social competition is caused by the weak awareness of learning. .Many professionals regard the learning in the universities as the only way to learn, while ignoring the self-improvement in the practice. What is worth noticing more is that not only technical employees in the printing industry but also all kinds of personnel in all the relevant industries should have the awareness to learn and learn in advance in order to make the enterprises achieve sustainable development. Especially in the "Internet $+"$ era of big data, knowledge and information comes in great amount, practitioners must keep learning, keep the awareness of learning to meet the job requirements.

Lack of Innovation. Rapid technological changes are taking place in digital printing industry almost every day. The pioneers in the digital printing industry cannot keep up with pace of technological innovation, just blindly observe the conventions and lack the awareness and the spirit of innovation, so they are frequently shut outside of the door to success. Of course, the awareness of innovation is not a technique that can be learned by receiving education but takes long time to cultivate. According to the current state of the digital printing industry practitioners, the training model lacks the innovative awareness of the teaching objects. The lack of innovative awareness is more obvious in the experienced practitioners because they have already developed a set idea and lack the motivation to innovate technology or marketing pattern.

Imperfect Training System. Current digital printing industry suffers a serious brain drain and the professionals are difficult to adapt to social competition, while entrepreneurs have the risk of 
high failure rate. The series of the problems are caused by the imperfect training system and call for the transformation from college training model to lifelong training model. Not only the vocational colleges need to build the students' career planning system but also the enterprises in the line of digital printing need to build the practitioners' career planning system. That is to say building evaluating system of career techniques can see to it that the training model of innovative and pioneering personnel cultivation in digital printing industry can meet the demand of the industrial development.

\section{Training Model of Innovative and Pioneering Personnel Cultivation in Digital Printing Industry}

With the advent of digital age of printing industry, innovation has become a source for maintaining industrial development. The rapid changes in digital printing technology caused the shift of training model from College training to lifelong education paradigm. Based on the reform of education ideas, targeted at innovation of training system, by means of practical teaching methods and teaching personnel, the individual demands are met in many teaching links to build the scientific training system of industrial talents to encourage talent technology innovation, self-employed and push the digital printing technology to a new developmental stage (Fig. 1).

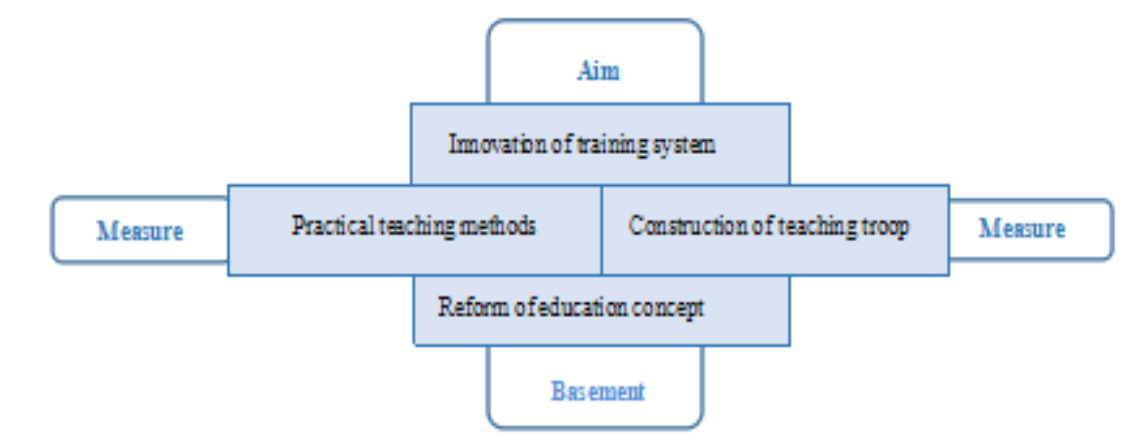

Figure 1: Training Model pattem of Innovative and Pioneering Personnel Cultivation in Digital Printing Industry

Reform of Education Concept. Digital printing industry 's two features of plateless printing and printing on-demand, which means that the industry needs skilled talents. And from management to human resources, to technology and design, we need a variety of assistant talents. Firstly, increase the proportion of the practice courses, which is very important, in constructing teaching model, giving students a signal that theory and practice is of equal importance to make education ideas of personnel training much healthier. Secondly, construct the idea of life-long education. The fast technology updating and development in the digital printing industry demands a number of people with different specialties. Therefore the shift from college education to life-long education is the only way to make employees in the printing industry to keep up with the development.

Innovation of Training System. Different industries have different personnel training systems. As light industry, digital printing industry demands personnel of higher vocational skills. Consequently it needs to break through the college training system limit, construct personnel training system from the perspective of industrial development. That is constructing evaluating system of vocational skills. The corresponding assessing standards are set up for the practitioners in the digital printing industry and its relevant industries according to their posts of duty. Variant education channels are constructed by means of higher education institution, vocational colleges and social skill training institution to meet the training demands of different people. Colleges and universities can practice their personnel training from the very basis while social institutions can practice their personnel training models by improving and assessing the practitioners' skills. At the same time, school and enterprise co-operated training modes can be taken into consideration.

Practical Teaching Methods. In the construction of the training model, teaching methods are extremely important. College education needs to lay more emphasis on practice courses in the 
teaching methods in order to improve education ideas of emphasizing theories and ignoring practice. The vocational colleges should especially enhance post practice and increase the class hours of on -the-job training. At the same time, the college employment centers should set up some corresponding auxiliary entrepreneurship courses, mainly targeted at transformation from the digital printing industry to new industries, such as individualization and "Internet $+"$. Schools should provide the students opportunities to get contact with new industrial technology to motivate students to get self- employed and lay a foundation for the students to step into the society. Venture creation counseling should be given to the business practitioners and the professionals preparing to set up a business to help the teaching objects to achieve self-employed by means of providing the latest technology and the most advanced programs.

Construction of Teaching Troop. In the process of constructing the personnel training system, what is the most important is the construction of teaching staff. From the perspective of the development of digital printing industry, and the self-employed demand, we should advocate construction of double-professionally -titled teaching staff. Based on the innovative measures described above in the personnel training system, school-enterprise cooperated model can be adopted in the construction of teaching troop. That is to say colleges and universities can send teachers to the enterprises to take a temporary post to obtain practical working experience, improve the teaching standards of practice courses while the enterprises can send the elite technologists to act as visiting teachers or teaching assistants to enhance the exchange between teachers and enterprise staff to achieve "win-win." outcome in personnel training.

\section{Conclusion}

Digital printing has become the trend of printing industry and personnel training in digital printing are extremely urgent. However, from the current state of digital printing professionals in our country, college and university personnel training mode needs to be transformed. The reform measures such as increasing practice teaching links, adopting school-enterprise cooperation and post-practice are becoming the necessary devices. At the same time we should introduce and train more double-professionally -titled teaching staff to improve teaching quality and help to move from college education to lifelong education.

\section{References}

[1] W.G.Ding, On Prepress Workflow,J,Printing Field, 2014 (6): 12-14. (In Chinese)

[2] L.Z.Lu, Printing on demand: What is Most Important,J, Printing Technology, 2015 (5): 15-17. (In Chinese)

[3] Y.M.Ou, The Analysis of Talent Demand and Training Situation of Digital Printing Technology Enterprise in Hubei Province,J, Journal of Wuhan Engineering Institute, 2013, 25 (3): 69-72. (In Chinese)

[4] X.H.Zhu, Internet Transformation of Traditional Printing Enterprises,J, Label Technology, 2015 (9): 35-37. (In Chinese)

[5] W.W.Zhu S.L.Zhu, Transformation of the Traditional Printing Enterprises under the Impact of Mobile Internet,J, Printing Quality and Standardization, 2015 (11): 17-21. (In Chinese)

[6] D.W.Yang Z.J.Xiao, Reflection and Exploration of the Mode of "Internet" in the Mode of Printing and Packaging Industry Transformation and Upgrading",J,Knowledge Economy, 2016 (9): 67-68.(In Chinese)

[7] W.Y.Huang Y.L.Huang H.G.Liu, The Influence of "Internet" Time on Packaging and Printing Enterprises and the Analysis of its Transformation,J, China Management Information, 2016, 19 (14). (In Chinese)

[8] C.G.Yuan, Analysis on the Construction of the Curriculum system of Entrepreneurship 
Education for College Students,J, Science and Technology Vision,2014 (33). (In Chinese)

[9] C.X.Liu X.H.Jiang, Research on the Network Entrepreneurial Model of College Students,J, Journal of Chifeng University, 2011 (9). (In Chinese)

[10]G.F.Wu, Research on. Entrepreneurship Education System for Local College and University Students, J,Education and Teaching Forum2015 (15). (In Chinese) 